\section{Abstractions}

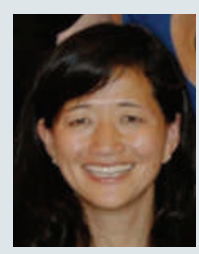

\section{LAST AUTHOR}

People with Down's syndrome, a disorder caused by having an extra copy of all or part of chromosome 21, tend to have lower-than-average cognitive ability and several characteristic physical features, as well as a shorter lifespan. But, much to the puzzlement of scientists, they are also less likely to develop solid cancers - tumours that form in tissues or organs. Theories proposed to explain this phenomenon include the possibility that many individuals with Down's syndrome die too early for such cancers to emerge, or that they aren't exposed to environmental risk factors or to stress and pressure, which have been linked to cancer. But Sandra Ryeom at the Children's Hospital Boston in Massachusetts and her team have discovered a biological basis for the protective effect of the disorder. Using mouse models, they found that the low solid-cancer rate is attributable at least in part to an extra copy of a gene whose product blocks the formation of new blood vessels - a process called angiogenesis - that typically feed tumours (see page 1126). Ryeom tells Nature more.

How does this gene block angiogenesis? We learned that DSCR1, a protein encoded by a gene on chromosome 21, suppresses one of the signals needed for new blood vessels to grow. When tumours are starting to form, they send out signals for blood-vessel growth. Humans can't usually fight that signal - it overrides the normal complement of DSCR1 that most of us have. But people with Down's syndrome have three copies of the gene, and we think that contributes to an ability to resist the tumour's signal.

\section{Were you surprised by your findings?}

Yes. When you do studies of cells in culture, you might express a gene 10,000 -fold more than in its natural state to determine its function. But the mice we used had just one extra copy of the DSCR1 gene and had more than $50 \%$ more DSCR1 protein than did the non-Down's-syndrome models. The question was whether that extra amount would be enough to shut down angiogenesis. It was.

What does this mean for human cancers? We've learned from earlier clinical trials of anti-angiogenic agents that stopping the formation of new blood vessels once a cancer has taken root may come too late to arrest tumour development. We think that there is potential to develop an antiangiogenic pill that could be taken every day - long before any cancer cells might begin to form - to stop tumours from growing in the first place. If we can show that DSCR1 blocks angiogenesis in the long term and has no side effects in mice, we will pass it on to industry. We're pursuing this now.

\title{
MAKING THE PAPER
}

\section{Dewashish Upadhyay}

\section{Ancient rocks bear traces of Earth's tumultuous early years.}

Cratons are the oldest, most stable parts of Earth's crust, and as such hold clues to Earth's early evolution. Dewashish Upadhyay, a geochemist now at the Indian Institute of Technology in Kharagpur, analysed the make-up of isotopes in rocks from India's Bastar craton and found that some of the rocks carry the signature of a differentiation event - the separation of materials with different geochemical properties. This event must have taken place during the first 400 million years of Earth's history, possibly when a magma 'ocean' covering the planet solidified.

The area encompassing the Bastar craton and the neighbouring Eastern Ghats Granulite Belt of southeastern India is rich in old rocks. The presence of alkaline igneous rock - a type of rock derived from Earth's mantle - marks the location where the Indian subcontinent split apart from another land mass 1.4 billion years ago and then collided with East Antarctica 1.1 billion years ago.

For his graduate project at the University of Bonn in Germany, Upadhyay made extended visits to the craton to collect samples and map the area. His initial analyses determined that the rocks were enriched in what he calls 'incompatible elements' - elements that prefer to remain in magma rather than become incorporated into crystallizing minerals.

During the course of this work, the geological field was stirred up by the discovery of rocks in southwest Greenland that provided evidence that a terrestrial magma ocean had crystallized to produce Earth's crust and mantle within 400 million years of the Solar System's formation. Isotopic analysis of the Greenland rocks had revealed an excess of neodymium-142 compared with terrestial standards, which indicated a separation of elements during that

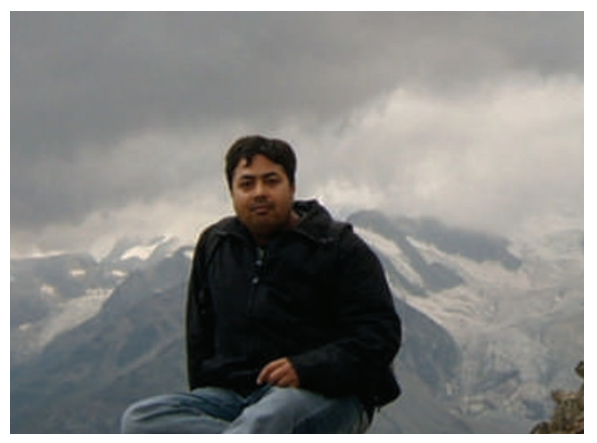

early, geochemically tumultuous time.

${ }^{142} \mathrm{Nd}$ is produced by the $\mathrm{a}$-decay of samarium-146, a now-extinct nuclide. Major geochemical differentiation events, such as the formation and crystallization of a magma ocean, could have fractionated samarium and neodymium, producing reservoirs with contrasting ${ }^{142} \mathrm{Nd}$ compositions. Because the Greenland reservoirs were rich in ${ }^{142} \mathrm{Nd}$, researchers started to look for a complementary reservoir with a ${ }^{142} \mathrm{Nd}$ deficit. And Upashyay wondered whether his rocks, rich as they were in incompatible elements, could have come from such a reservoir.

To test his suspicions, he needed to measure the ratio of ${ }^{142} \mathrm{Nd}$ to ${ }^{144} \mathrm{Nd}$, a naturally occurring radioisotope that serves as a reference point. "If we can measure variation in ${ }^{142} \mathrm{Nd}$, it implies there was some sort of a differentiation event that fractionated samarium from neodymium," Upadhyay says.

Upadhyay got the opportunity to do this analysis as a postdoc in Klaus Mezger's laboratory at the University of Münster in Germany. It revealed a deficit in ${ }^{142} \mathrm{Nd}$ in four out of seven rock samples. He and his coauthors concluded that the rocks were derived from a source formed during Hadean time - Earth's earliest geological aeon - and that some such Hadean reservoirs may be preserved in the mantle beneath cratons (see page 1118).

Now Upadhyay is back in India as a faculty member. He is working to set up his own lab, which will be the first in the country able to do the kind of isotopic analysis required to track elements - and so Earth's history.

\section{FROM THE BLOGOSPHERE}

Academic reports may

sound alarm bells, but do not necessarily spur governments into action. In a post on

Indigenus, Nature India editor Subhra Priyadarshini highlights two recent publications on the effects of climate change on vulnerable human populations (http://tinyurl.com/nqvq3t).

$A$ report produced by the United Nations in collaboration with Columbia University in
New York and the aid agency CARE International predicts large-scale migrations, and disruption to farming and water supplies, as the Himalayan alpine glaciers melt. Meanwhile, the London-based International Institute of Environment and Development, has published a book saying that a top priority, and no small task, is to "remedy deficits in infrastructure" in cities where "at least half of the population lacks piped water sewers, drains, health care or emergency services," writes Pryadarshini.

She notes that past academic reports and press coverage of some of the world's first climate-change refugees have done little to change their plight: "The migrants from these sinking islands [in the Bay of Bengal] have not yet been recognised as vulnerable." 